\title{
Sensitivity and Specificity of a Short Questionnaire to Screen Frailty in the Community-Dwelling Older Population
}

\author{
Alessandra Capanna1, Paola Scarcella², Francesco Gilardi'2, Sandro Mancinelli2, \\ Leonardo Palombi ${ }^{2}$, Maria Cristina Marazzi ${ }^{3}$, Fabio Riccardi ${ }^{2}$, Giuseppe Liotta ${ }^{2}$ \\ ${ }^{1}$ School of Specialization in Hygiene and Preventive Medicine, University of Rome Tor Vergata, Rome, Italy \\ ${ }^{2}$ Department of Biomedicine and Prevention, University of Rome Tor Vergata, Rome, Italy \\ ${ }^{3}$ LUMSA University, Rome, Italy \\ Email: capannalessandra@gmail.com
}

How to cite this paper: Capanna, A., Scarcella, P., Gilardi, F., Mancinelli, S., Palombi, L., Marazzi, M.C., Riccardi, F. and Liotta, G. (2018) Sensitivity and Specificity of a Short Questionnaire to Screen Frailty in the Community-Dwelling Older Population. Advances in Aging Research, 7, 52-63. https://doi.org/10.4236/aar.2018.73005

Received: March 10, 2018

Accepted: May 28, 2018

Published: May 31, 2018

Copyright $\odot 2018$ by authors and Scientific Research Publishing Inc. This work is licensed under the Creative Commons Attribution International License (CC BY 4.0).

http://creativecommons.org/licenses/by/4.0/

(c) (i) Open Access

\begin{abstract}
Introduction. Frailty represents a major risk factor for death and Use of Hospital Services (UHS) among older adults. A simple tool to detect frailty might permit stratification of the community-dwelling older population according to the risk of negative outcomes. The present study aims at determining the sensitivity and specificity in predicting mortality and UHS of the Short Functional Geriatric Evaluation (SFGE), a short questionnaire to screen for frailty in community-dwelling older citizens. Methods. The study is a secondary analysis of all the data collected through an observational longitudinal cohort study carried out in Lazio region (Italy). The SFGE is compared with the Functional Geriatric Evaluation (FGE) questionnaire to define sensitivity and specificity for mortality and for UHS during the first year following its administration. Results. The SFGE classifies $36.3 \%$ of the respondents as frail and shows a sensitivity of $90.4 \%$ and a specificity of $78.3 \%$ compared to the FGE (area under the ROC: 0.928; CL95\%: 0.910 - 0.947; p-value < 0.001). Those respondents identified by the SFGE as frail also include some of those classified by the FGE as pre-frail, who also show a high rate of UHS. The results show that the SFGE score predicts the UHS more accurately than it does the mortality rate. Conclusion. The SFGE identifies as frail a larger portion of the enrolled population than the FGE. Those people so identified show a high rate of UHS. Because of its easy and quick administration, it can be considered a useful primary screening tool but it must be followed up with a more extensive assessment of those identified as frail. The small time needed to fill in the tool and the possibility of administering it by telephone makes the SFGE a useful tool to screen for frailty and to plan the provision of care services at both individual and population level.
\end{abstract}




\section{Keywords}

Frailty, Short Questionnaire, Community-Dwelling People, Older People, Screening

\section{Introduction}

In the context of the rapid ageing of the global population, the concept of older adults' frailty has become a very important issue not merely in clinical settings but also for Public Health. In fact, identifying those elderly who are already frail, or close to become so, represents the first step towards planning appropriate public health interventions and developing suitable prevention programmes [1] [2].

Frailty is a multidimensional and dynamic condition characterized by a reduced ability to deal with acute physical, psychological and socio-economic stressors and/or to perform the normal activities of daily life [3] [4] [5]. It is widely recognized that frailty aggravates the risk of poor outcomes (e.g. death, loss of autonomy, functional impairment and hospitalization) [6] [7] and that it develops within various domains (e.g. physical, psychological, socio-economic, environmental status) [8] [9] [10].

Although numerous frailty tools have already been developed in order to screen older adults living in the community, a gold standard instrument to measure and to screen for frailty has yet to come. A two-step model with two tools, a first and second level questionnaire [11], should be used in order to screen for frailty in the community setting. The first level questionnaire is a screening tool for the community-dwelling older population; the second level questionnaire is a more detailed test, directed at those identified as frail by the first level survey, in order to plan the provision of a personalized care package.

The idea of testing a huge number of elderly citizens, however, raises practical concerns. First of all, such a time-consuming activity can be implemented only if it provides crucial information to improve health, either at an individual or at a population level. Secondly and closely related to the first point, there is the question of the availability of a reliable short questionnaire. Several researchers are committed to find a model for providing effective community care services [12]-[17]; the screening of frailty at population level with a short and reliable tool is a first step to achieve this goal.

The present study aims at defining the short-term sensitivity and specificity in predicting mortality and Use of Hospital Services (UHS) of the Short Functional Geriatric Evaluation (SFGE), a first level questionnaire intended to screen for frailty in community-dwelling older adults.

\section{Methods}

The study is a secondary analysis of data gathered for the observational longitu- 
dinal cohort study carried out in the Lazio region (Italy) [18], by the Biomedicine and Prevention Department of the University of "Tor Vergata", and approved by the Independent Ethical Committee of the University of Rome "Tor Vergata".

The inclusion criteria were to be living in Lazio region, to be more than 64 years old and to be living within the community. Those living in an institution were excluded. The cohort is made up by 1,342 subjects enrolled in 2014, of whom 1,282 completed the one-year follow up.

The Functional Geriatric Evaluation (FGE) questionnaire for the assessment of frailty was administered to all the participants. The FGE questionnaire is a multidimensional tool that deals with biological and non-biological domains (physical and mental health, social and economic resources and functional status). The final score could be divided into two categories: "robust" (FGE > 49) and "frail" (FGE $\leq 49$ ). As shown by previous papers, the frail group has a greater risk of adverse events than the group of the robust; in fact the FGE score has been proved to be an effective predictor of death, of hospitalization and of institutionalization over a span of from 1 to 5 years from the point of observation [19] [20]. The FGE score varies from -118 to +98 , with a range of 217 points.

The SFGE questionnaire was developed from the FGE tool [14] [21]. The items of FGE included in the SFGE (shown in Table 1) were selected by matching each FGE element with the UHS. The UHS rate was calculated by adding the cumulative amount of hospitalizations per year to the number of Emergency Department Visits (EDV) not resulting in hospital admission and to the use of outpatient hospital services occurring during the one year follow up. All the variables found to have statistical significance to the outcome were included in the final version of the SFGE. The weight of each variable was reported to be the

Table 1. The items of FGE included in the SFGE.

\begin{tabular}{ll}
\hline Item & Description of item \\
\hline Age & Age $<75$ years; $75 \leq$ age $<85$ years; age $\geq 85$ years \\
Education & Primary education vs. secondary education \\
Living arrangements & $\begin{array}{l}\text { Alone/living with spouse/living with others (son or daughter/other rela- } \\
\text { tives/friends/paid assistant) }\end{array}$ \\
Informal care & Availability of someone able to help in case of need vs. lack thereof \\
Social network & $\begin{array}{l}\text { Participation to social activities vs. lack thereof } \\
\text { Availability of home care services vs. lack thereof }\end{array}$ \\
Economic condition & Monthly income sufficient for basic needs vs. lack thereof \\
Energy \& drive & $\begin{array}{l}\text { Being very sad, apathetic or slowed in their actions (hypoactive) or restless, } \\
\text { agitated or talkative (hyperactive) vs. normal mood }\end{array}$ \\
Mental status & $\begin{array}{l}\text { Severe confusion (do not able to live alone) vs. other condition } \\
\text { 1) To be able to take the shower/bath alone vs. to be unable } \\
\text { 2) To be able to get out from the house vs. to be unable } \\
\text { 3) To be able to get off the bed vs. to be unable }\end{array}$
\end{tabular}


score of that variable. The variables "Living arrangements" and "Education" were included, because of their relevance respectively to the demand for care and as a proxy of socio-economic level. Overall, the SFGE is a synthetic version of the FGE that evaluates only 10 ordinal variables with a score that ranges from -6 to +27 , a 34-point range. The SFGE score scale is the result of the analysis of sensitivity and specificity values in relation to the FGE results. After a one year follow up, two outcomes were observed: death and the UHS.

\section{Statistical Analyses}

The software Statistical Package for Social Science (SPSS) was used to analyze the data. A p-value $<0.005$ was considered to be statistically significant. The Pearson Chi-Square, the K-value for concordance, parametric and non-parametric test to assess the difference of means amongst variables according to the values distribution, the Receiver Operating Characteristic (ROC) curve and the Cox Proportional Risk analysis were performed.

\section{Results}

The sample was made up of 690 females (53.8\%; mean age: 76.6 years with a SD of 7.3) and 592 males (46.2\%; mean age: 76.3 years with a SD of 7.1). During the baseline assessment with the FGE questionnaire, 1,008 individuals were classified as "robust" (78.8\%) while 272 were classified as "frail" (21.2\%).

The results of the SFGE 10 items are summarized in Table 2. A ROC curve was performed in order to choose the appropriate cut-off level for frailty for the SFGE questionnaire. Thus, based on the best combination "sensitivity" (90.4\%) against "specificity" (78.3\%), the value zero was chosen as the most appropriate cut-off level (area under the curve: 0.928; CL95\%: 0.910 - 0.947; p-value < 0.001). Using this cut-off, the SFGE questionnaire classified 465 individuals as frail (SFGE score $>0$ ), $36.3 \%$ of the sample ( $\mathrm{K}$ value $=0.54$, moderate concordance).

As shown in Table 3, the two questionnaires disagree for 26 persons who were "frail" for the FGE and "robust" for the SFGE (category C-2) and for 219 persons who were "robust" for the FGE and "frail" for the SFGE (category C-3). The hospitalization rates of both groups were higher than that of the group classified as "robust" by both questionnaires, which would not have been expected for those citizens classified as "robust" by FGE (Table 4, Kruskal-Wallis Test, p = 0.006; Mann-Whitney U Test, not shown in the table, between categories C-1 and $\mathrm{C}-3, \mathrm{p}=0.041$ ). In fact, the category $\mathrm{C}-3$ showed a hospitalization rate more similar to the category C-4 (the individuals classified as "frail" by both questionnaires) than to C-1 (the individuals classified as "robust"): the SFGE score that generated the classification was worse in all the SFGE items for the C-3 subjects compared with the $\mathrm{C}-1$ ones.

At the same time the group made up of 26 persons considered "robust" by the SFGE and "frail" by the FGE showed the highest UHS rate (Table 4). The main difference between this group and the group classified as "robust" by both questionnaires was the level of co-morbidity (4.1 diseases on average vs. 3.0 among 
Table 2. Result of the short functional geriatric evaluation.

\begin{tabular}{|c|c|c|}
\hline Variables & $\underset{\text { (total: } 1282 \text { ) }}{\mathrm{N}}$ & $\%$ \\
\hline \multicolumn{3}{|l|}{ Age } \\
\hline Age $<75$ years & 658 & 51.4 \\
\hline $75 \leq$ age $<85$ years & 480 & 37.4 \\
\hline Age $\geq 85$ years & 144 & 11.2 \\
\hline \multicolumn{3}{|l|}{ Education } \\
\hline Over the first level of secondary school & 260 & 20.3 \\
\hline Under the first level of secondary school & 1022 & 79.7 \\
\hline \multicolumn{3}{|l|}{ Living arrangements } \\
\hline Alone & 265 & 20.7 \\
\hline With son or daughter/other relatives/friend/paid assistant & 351 & 27.3 \\
\hline With spouse & 666 & 52.0 \\
\hline \multicolumn{3}{|l|}{ Informal care } \\
\hline Yes & 1198 & 93.4 \\
\hline No & 84 & 6.6 \\
\hline \multicolumn{3}{|l|}{ Social network } \\
\hline Yes & 851 & 66.4 \\
\hline No & 431 & 33.6 \\
\hline \multicolumn{3}{|l|}{ Homecare } \\
\hline Yes & 635 & 49.5 \\
\hline No & 647 & 50.5 \\
\hline \multicolumn{3}{|l|}{ Economic condition (monthly income is sufficient) } \\
\hline Yes & 490 & 38.2 \\
\hline No & 792 & 61.8 \\
\hline \multicolumn{3}{|l|}{ Energy \& Drive } \\
\hline Present & 1026 & 80.0 \\
\hline Absent & 256 & 20.0 \\
\hline \multicolumn{3}{|l|}{ Mental status severe confusion in not present) } \\
\hline Yes & 1258 & 98.1 \\
\hline No & 24 & 1.9 \\
\hline \multicolumn{3}{|l|}{ Functional status } \\
\hline \multicolumn{3}{|l|}{ Able to take the shower/bath alone } \\
\hline Yes & 1034 & 80.7 \\
\hline No & 248 & 19.3 \\
\hline \multicolumn{3}{|l|}{ Able to get out from the house } \\
\hline Yes & 1226 & 95.6 \\
\hline No & 56 & 4.4 \\
\hline \multicolumn{3}{|l|}{ Able to get off the bed } \\
\hline Yes & 1220 & 95.2 \\
\hline No & 62 & 4.8 \\
\hline
\end{tabular}


Table 3. Contingency table that compares the FGE and SFGE questionnaires.

\begin{tabular}{ccccc}
\hline & \multicolumn{3}{c}{ Functional Geriatric Evaluation } \\
\cline { 3 - 5 } & & Frail & Robust & Total \\
\hline Short Functional & Frail & $246(90.4 \%)$ & $219(21.7 \%)$ & $465(36.3 \%)$ \\
Geriatric Evaluation & Robust & $26(9.6 \%)$ & $789(78.3 \%)$ & $815(63.7 \%)$ \\
Total & & $272(21.2 \%)$ & $1008(78.8 \%)$ & $1280(100 \%)$ \\
Missing & & & & 2 \\
\hline
\end{tabular}

Table 4. Use of Hospital Service (UHS) rates.

\begin{tabular}{|c|c|c|c|c|c|c|c|c|c|c|c|}
\hline \multirow[t]{2}{*}{ Category } & & & \multirow[t]{2}{*}{ No } & \multicolumn{2}{|c|}{$\begin{array}{l}\text { ED visits without } \\
\text { hospitalization }\end{array}$} & \multicolumn{2}{|c|}{ Hospitalization } & \multicolumn{2}{|c|}{$\begin{array}{c}\text { Day Hospital } \\
\text { visit }\end{array}$} & \multicolumn{2}{|c|}{ Total } \\
\hline & & & & Rate & SD & Rate & SD & Rate & SD & Rate & SD \\
\hline$C-1$ & $\begin{array}{l}\text { FGE } \\
\text { SFGE }\end{array}$ & Robust & 791 & 342.6 & 764.8 & 140.9 & 536.4 & 80.7 & 334.0 & 567.4 & 1070.3 \\
\hline $\mathrm{C}-2$ & $\begin{array}{l}\text { FGE } \\
\text { SFGE }\end{array}$ & $\begin{array}{c}\text { Frail } \\
\text { Robust }\end{array}$ & 26 & 423.1 & 702.7 & 935.4 & 1937.5 & 169.4 & 514.8 & 1640.6 & 2386.9 \\
\hline C-3 & $\begin{array}{l}\text { FGE } \\
\text { SFGE }\end{array}$ & $\begin{array}{c}\text { Robust } \\
\text { Frail }\end{array}$ & 219 & 324.2 & 789.7 & 246.8 & 954.8 & 82.2 & 374.1 & 663.9 & 1324.1 \\
\hline C-4 & $\begin{array}{l}\text { FGE } \\
\text { SFGE }\end{array}$ & Frail & 246 & 329.3 & 955.4 & 329.9 & 955.4 & 99.7 & 585.7 & 1012.6 & 2316.5 \\
\hline & $\mathrm{p}-\mathrm{v}$ & ralue & & & & & 001 & & 543 & & 009 \\
\hline
\end{tabular}

Legend. FGE: Functional Geriatric Evaluation; SFGE: Short Functional Geriatric Evaluation; ED: Emergency Department.

the "robust" individuals) and the initial functional impairment, as indicated by the higher percentage of individuals not able to take a bath/shower alone. Figure 1 shows the correlation between the FGE and the SFGE scores: $86.9 \%$ of the cases which the SFGE classified as "frail" had an FGE score between 50 and 70 (mean age 80.0 years; mean FGE score $=62.03$; $\mathrm{SD} \pm 6.88$; correlation coefficient value: $-0.851 ; \mathrm{p}$ value $<0.001)$. This score identifies subjects close to the frail condition, a category which can be defined as pre-frail.

The survival analysis adjusted for gender, age and multi-morbidities shows that while the FGE classification of frailty can be predictive of mortality during the first year of follow up ( $R R=6.2$; CL95: $3.2-12.1)$, the SFGE classification shows no statistically meaningful association $(\mathrm{RR}=1.6$; CL95: $0.8-3.1)$.

\section{Discussion}

Public Health should consider frailty a priority, due to its strong relationship with the increase of UHS by older adults and to its association with some chronic degenerative diseases [1] [20] [22]. The screening for frailty allows identification of the population at risk of adverse health outcomes and represents an important support in planning health and social services [23]. Using a simplified frailty index is the most appropriate way to screen the population: the SFGE is a 


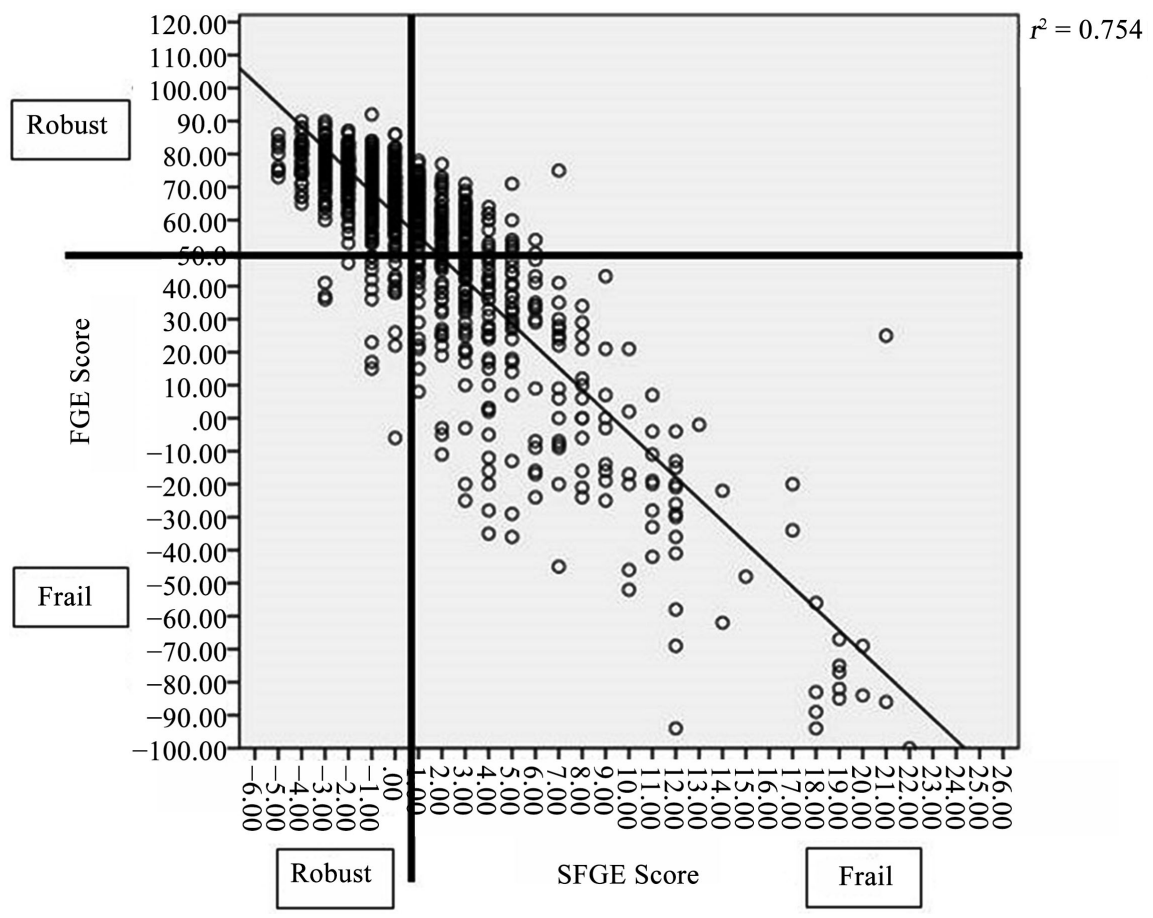

Figure 1. SFGE/FGE scores comparison.

simple instrument, administrable by telephone that enables the health authorities to reach a relevant proportion of the community-dwelling older adult population and to identify with high sensitivity and acceptable specificity those individuals at a higher risk of negative outcomes. Finally, it can also be administered by personnel with only a high school diploma, increasing the number of workers potentially available for the process of implementing the screening procedure.

The FGE is highly predictive of negative outcomes, even in the short-term, so that it represents a very good basis to develop a shorter tool. The FGE classifies as frail the $21.2 \%$ of the interviewed, while the SFGE identifies as frail a larger portion of the same population (36.3\%).

The SFGE differs from the FGE questionnaire in that it has a smaller number of questions, and in the nature of the final score: the score generated by the socio-economic items of the FGE questionnaire accounts for $26 \%$ of the FGE total score but for $47 \%$ of the SFGE total score. The higher percentage of frail individuals identified by the SFGE than by the FGE questionnaire then derives from the different balance between physical, mental and functional status relative to socio-economic resources. As shown in the literature, socio-economic resources play a crucial role as determinants of population health [24] [25]; the impact of socio-economic frailty in the generation of higher rates of UHS in an environment with a low level of care services in the community has also been proved [26]. The analysis of non-biological frailty may play an essential role in the assessment of the burden of the health care needed by community-dwelling older adults, as well as in the planning of public health interventions. In fact, nowadays, several studies have looked at psychological and socioeconomic domains as 
determinants of frailty [27]-[32]. The gap of sensitivity of the SFGE compared with the FGE questionnaire seems mainly to be due to a misclassification of individuals with multiple physical impairments, evidenced by the presence of high co-morbidity without a severe impairment of functional status. In order to improve the sensitivity of the tool, a variable dealing with physical health easily detectable during a phone call should be included in the assessment. The number of pills per day taken by the interviewed could be an effective, even if indirect, indicator of the presence of co-morbidity [33] [34]. The low specificity of the tool is acceptable for a first level population screening carried out within the framework of a public health approach, with the main objective being to minimize false negative results even at the cost of increasing the number of false positives.

This study helps to highlight the pre-frail status [35] [36], which is mainly marked by a lack of socio-economic resources, with initial psycho-physical impairment, and is associated with a higher rate of UHS than the robust status. This is in agreement with the observation that a lack of social resources is one of the main determinants of the UHS [36]. These outcomes indicate a potentially major impact on Public Health planning: the provision for social care is in fact able to reduce the hospitalization rate [37], a consequence of the role played by socio-economic resources in the demand for hospital care by older adults. The SFGE questionnaire explores socio-economic areas more extensively than other first level questionnaires. It may thus be better able to predict the demand for hospital care, even if further studies with longer follow up are needed to verify this hypothesis. The SFGE "frail" group may be the target of health promotion and of care intervention aimed at managing frailty at a community level. The SFGE does not show statistical significance in the short-term assessment of the risk of death, probably because of the inclusion in the frail group of the pre-frail subjects with a lower risk of death.

\section{Conclusion}

The SFGE is a tool to screen frailty at a community level and has a good short-term sensitivity and specificity for UHS. The relevance of socio-economic resources that account for $47 \%$ of the SFGE score makes this tool appropriate for use at a community level, where these resources are strongly correlated with the demand for care services. Further studies are needed to improve the sensitivity of the tool in order to reduce the proportion of false negatives. A public health approach to the management of frailty could also contribute to the medium-and long-term sustainability of health systems by identifying and counteracting the conditions that generate the highest demand for health care. Identifying as many frail individuals as possible becomes of utmost importance when planning interventions aimed at preventing or managing frailty at community level.

\section{References}

[1] World Health Organization. (2015) Ageing and Health. 
http://www.who.int/mediacentre/factsheets/fs404/en/

[2] Clegg, A. and Young, J. (2015) Frailty and Organization of Health and Social Care. Interdisciplinary Topics in Gerontology and Geriatrics, 41, 161-173.

[3] Brown, I., Renwick, R. and Raphael, D. (1995) Frailty: Constructing a Common Meaning, Definition, and Conceptual Framework. International Journal of Rehabilitation Research, 18, 93-102. https://doi.org/10.1097/00004356-199506000-00001

[4] Xue, Q.L. (2011) The Frailty Syndrome: Definition and Natural History. Clinics in Geriatric Medicine, 27, 1-15. https://doi.org/10.1016/j.cger.2010.08.009

[5] Gill, T.M., Gahbauer, E.A., Allore, H.G. and Han, L. (2006) Transitions between Frailty States among Community-Living Older Persons. Archives of Internal Medicine, 166, 418-423. https://doi.org/10.1001/archinte.166.4.418

[6] Lee, L., Heckman, G. and Molnar, F.J. (2015) Frailty: Identifying Elderly Patients at High Risk of Poor Outcomes. Canadian Family Physician, 61, 227-231.

[7] Raphael, D., Cava, M., Brown, I., Renwick, R., Heathcote, K., Weir, N., Wright, K. and Kirwan, L. (1995) Frailty: A Public Health Perspective. Canadian Journal of Public Health, 86, 224-227.

[8] Gobbens, R.J., Luijkx, K.G., Wijnen-Sponselee, M.T. and Schols, J.M. (2010) Towards an Integral Conceptual Model of Frailty. The Journal of Nutrition Health and Aging, 14, 175-181. https://doi.org/10.1007/s12603-010-0045-6

[9] Gobbens, R.J., van Assen, M.A., Luijkx, K.G., Wijnen-Sponselee, M.T. and Schols, J.M. (2010) Determinants of Frailty. Journal of the American Medical Directors Association, 11, 356-364. https://doi.org/10.1016/j.jamda.2009.11.008

[10] Coelho, T., Paúl, C., Gobbens, R.J. and Fernandes, L. (2015) Determinants of Frailty: The Added Value of Assessing Medication. Frontiers in Aging Neuroscience, 7, 56. https://www.frontiersin.org/articles/10.3389/fnagi.2015.00056/full https://doi.org/10.3389/fnagi.2015.00056

[11] Clegg, A., Rogers, L. and Young, J. (2015) Diagnostic Test Accuracy of Simple Instruments for Identifying Frailty in Community-Dwelling Older People: A Systematic Review. Age and Ageing, 44, 148-152. https://doi.org/10.1093/ageing/afu157

[12] Chen, S., Honda, T., Chen, T., Narazaki, K., Haeuchi, Y., Supartini, A. and Kumagai, S. (2015) Screening for Frailty Phenotype with Objectively-Measured Physical Activity in a West Japanese Suburban Community: Evidence from the Sasaguri Genkimon Study. BMC Geriatrics, 15, 36.

https://bmcgeriatr.biomedcentral.com/articles/10.1186/s12877-015-0037-9 https://doi.org/10.1186/s12877-015-0037-9

[13] O’Caoimh, R., Cornally, N., Weathers, E., O’Sullivan, R., Fitzgerald, C., Orfila, F., Clarnette, R., Paúl, C. and Molloy, D.W. (2015) Risk Prediction in the Community: A Systematic Review of Case-Finding Instruments that Predict Adverse Healthcare Outcomes in Community-Dwelling Older Adults. Maturitas, 82, 3-21. https://doi.org/10.1016/j.maturitas.2015.03.009

[14] Liotta, G., Orfila, F., Vollenbroek-Hutten, M., Roller-Winsberger, R., Illario, M., Musian, D., Alvino, S., O'Caoimh, R., Cano, A., Molloy, W., Iaccarino, G., Marazzi, M.C., Inzerilli, M.C., Madaro, O., Paul, C., Csonka, P., Vince, A.C., Menditto, E., Maggio, M., Scarcella, P., Gilardi, F., Lucaroni, F., Abete, P., Girardi, V., Barra, R. and Palombi, L. (2016) The European Innovation Partnership on Active and Healthy Ageing Synergies: Protocol for a Prospective Observational Study to Measure the Impact of a Community-Based Program on Prevention and Mitigation of Frailty (ICP-PMF) in Community-Dwelling Older Adults. Translational Medicine (@) UniSa, 15, 53-66. 
[15] Akın, S., Mazıcıoglu, M.M., Mucuk, S., Gocer, S., Deniz Şafak, E., Arguvanli, S. and Ozturk, A. (2015) The Prevalence of Frailty and Related Factors in Community-Dwelling Turkish Elderly according to Modified Fried Frailty Index and FRAIL Scales. Aging Clinical and Experimental Research, 27, 703-709. https://doi.org/10.1007/s40520-015-0337-0

[16] Buttery, A.K., Busch, M.A., Gaertner, B., Scheidt-Nave, C. and Fuchs, J. (2015) Prevalence and Correlates of Frailty among Older Adults: Findings from the German Health Interview and Examination Survey. BMC Geriatrics, 15, 22.

https://www.ncbi.nlm.nih.gov/pmc/articles/PMC4357063/pdf/12877_2015_Article_ 22.pdf https://doi.org/10.1186/s12877-015-0022-3

[17] O’Caoimh, R., Gao, Y., Svendrovski, A., Healy, E., O’Connell, E., O’Keeffe, G., Cronin, U., Igras, E., O’Herlihy, E., Fitzgerald, C., Weathers, E., Leahy-Warren, P., Cornally, N. and Molloy, D.W. (2015) The Risk Instrument for Screening in the Community (RISC): A New Instrument for Predicting Risk of Adverse Outcomes in Community Dwelling Older Adults. BMC Geriatrics, 15, 92.

https://www.ncbi.nlm.nih.gov/pmc/articles/PMC4520060/ https://doi.org/10.1186/s12877-015-0095-Z

[18] Liotta, G., O’Caoimh, R., Gilardi, F., Proietti, M.G., Rocco, G., Alvaro, R., Scarcella, P., Molloy, D.W., Orlando, S., Mancinelli, S., Palombi, L., Stievano, A. and Marazzi, M.C. (2017) Assessment of Frailty in Community-Dwelling Older Adults Residents in the Lazio Region (Italy): A Model to Plan Regional Community-Based Services. Archives of Gerontology and Geriatrics, 68, 1-7. https://doi.org/10.1016/j.archger.2016.08.004

[19] Scarcella, P., Liotta, G., Marazzi, M.C., Carbini, R. and Palombi, L. (2005) Analysis of Survival in a Sample of Elderly Patients from Ragusa, Italy on the Basis of a Primary Care Level Multidimensional Evaluation. Archives of Gerontology and Geriatrics, 40, 147-156. https://doi.org/10.1016/j.archger.2004.07.004

[20] Gilardi, F., Palombi, L., Scarcella, P., Lucaroni, F., Proietti, M.G., Saffioti, C., Morbidelli, S., D’Ascanio, I., Mancinelli, S., Marazzi, M.C. and Liotta, G. (2016) Impact of Frailty on the Hospitalization in a Sample of Community-Dwelling Older Adults in Rome. European Journal of Public Health, 26, 261. https://doi.org/10.1093/eurpub/ckw171.059

[21] Gilardi, F., Scarcella, P., D’Anna, G., Di Gennaro, L., Passini, V., Mancinelli, S. and Liotta, G. (2017) La misurazione della fragilità. Questionari multidimensionali di screening a confronto. 50 th National Congress of "Società Italiana di Igiene", No. 332, 669. http://www.igienistionline.it/docs/2017/49atti.pdf

[22] World Health Organization (2015) World Report on Ageing and Health. http://apps.who.int/iris/bitstream/10665/186463/1/9789240694811_eng.pdf?ua=1

[23] Cesari, M., Prince, M., Thiyagarajan, J.A., De Carvalho, I.A., Bernabei, R., Chan, P., Gutierrez-Robledo, L.M., Michel, J.P., Morley, J.E., Ong, P., Rodriguez Manas, L., Sinclair, A., Won, C.W., Beard, J. and Vellas, B. (2016) Frailty: An Emerging Public Health Priority. Journal of the American Medical Directors Association, 17, 188-192. http://www.jamda.com/article/S1525-8610(15)00766-5/fulltext

[24] Braveman, P. and Gottlieb, L. (2014) The Social Determinants of Health: It's Time to Consider the Causes of the Causes. Public Health Reports, 129, 19-31. https://doi.org/10.1177/00333549141291S206

[25] Jakab, Z. and Marmot, M. (2012) Social Determinants of Health in Europe. The Lancet, 379, 103-105. https://doi.org/10.1016/S0140-6736(11)61511-0 
[26] Gilardi, F., Scarcella, P., Proietti, M.G., Rocco, G., Capanna, A., Mancinelli, S., Marazzi, M.C., Palombi, L. and Liotta, G. (2018) Identify the Older Adults Showing Higher Rate of Death and Hospital Services Use According to Frailty: A Clusters Analysis in a Longitudinal Cohort Study. European Journal of Public Health. https://doi.org/10.1093/eurpub/cky006

[27] Gutiérrez-Robledo, L.M. and Avila-Funes, J.A. (2012) How to Include the Social Factor for Determining Frailty? The Journal of Frailty \& Aging, 1, 13-17.

[28] Lang, I.A., Hubbard, R.E., Andrew, M.K., Llewellyn, D.J., Melzer, D. and Rockwood, K. (2009) Neighborhood Deprivation, Individual Socioeconomic Status, and Frailty in Older Adults. Journal of the American Geriatrics Society, 57, 1776-1780. https://doi.org/10.1111/j.1532-5415.2009.02480.x

[29] Etman, A., Kamphuis, C.B., van der Cammen, T.J., Burdorf, A. and van Lenthe, F.J. (2015) Do Lifestyle, Health and Social Participation Mediate Educational Inequalities in Frailty Worsening? European Journal of Public Health, 25, 345-350. https://www.ncbi.nlm.nih.gov/pmc/articles/PMC4447813/pdf/cku093.pdf https://doi.org/10.1093/eurpub/cku093

[30] Szanton, S.L., Seplaki, C.L., Thorpe, R.J., Allen, J.K. and Fried, L.P. (2010) Socioeconomic Status Is Associated with Frailty: The Women's Health and Aging Studies. Journal of Epidemiology and Community Health, 64, 63-67. https://www.ncbi.nlm.nih.gov/pmc/articles/PMC2856660/pdf/nihms-183799.pdf https://doi.org/10.1136/jech.2008.078428

[31] Makizako, H., Shimada, H., Tsutsumimoto, K., Lee, S., Doi, T., Nakakubo, S., Hotta, R. and Suzuki, T. (2015) Social Frailty in Community-Dwelling Older Adults as a Risk Factor for Disability. Journal of the American Medical Directors Association, 16, 1003.e7-1003.e11. https://doi.org/10.1016/j.jamda.2015.08.023

[32] Dent, E. and Hoogendijk, E.O. (2014) Psychosocial Factors Modify the Association of Frailty with Adverse Outcomes: A Prospective Study of Hospitalised Older People. BMC Geriatrics, 14, 108. https://doi.org/10.1186/1471-2318-14-108 https://www.ncbi.nlm.nih.gov/pmc/articles/PMC4190287/pdf/12877_2014_Article_ 1043.pdf

[33] McDonald, M.V., Peng, T.R., Sridharan, S., Foust, J.B., Kogan, P., Pezzin, L.E. and Feldman, P.H. (2013) Automating the Medication Regimen Complexity Index. Journal of the American Medical Informatics Association: JAMIA, 20, 499-505. https://doi.org/10.1136/amiajnl-2012-001272

[34] Libby, A.M., Fish, D.N., Hosokawa, P.W., Linnebur, S.A., Metz, K.R., Nair, K.V., Saseen, J.J., Vande Griend, J.P., Vu, S.P. and Hirsch, J.D. (2013) Patient-Level Medication Regimen Complexity across Populations with Chronic Disease. Clinical Therapeutics, 35, 385-398.e1. https://doi.org/10.1016/j.clinthera.2013.02.019

[35] Ilinca, S. and Calciolari, S. (2015) The Patterns of Health Care Utilization by Elderly Europeans: Frailty and Its Implications for Health Systems. Health Services Research, 50, 305-320. https://doi.org/10.1111/1475-6773.12211 https://www.ncbi.nlm.nih.gov/pmc/articles/PMC4319884/pdf/hesr0050-0305.pdf

[36] Fairhall, N., Kurrle, S.E., Sherrington, C., Lord, S.R., Lockwood, K., John, B., Monaghan, N., Howard, K. and Cameron, I.D. (2015) Effectiveness of a Multifactorial Intervention on Preventing Development of Frailty in Pre-Frail Older People: Study Protocol for a Randomised Controlled Trial. BMJ, 5, e007091.

https://www.ncbi.nlm.nih.gov/pmc/articles/PMC4322196/pdf/bmjopen-2014-00709 1.pdf

https://doi.org/10.1136/bmjopen-2014-007091 
[37] Liotta, G., Inzerilli, M.C., Palombi, L., Bianchini, A., Di Gennaro, L. and Marazzi, M.C. Impact of Social Care on Hospital Admissions in a Sample of Community-Dwelling Older Adults: Results of a Quasi-Experimental Intervention Program. Annali Di Igiene. (In Press) 